\title{
The metrological research of the Machu Picchu site. Application of a cosine quantogram method for 3D laser data
}

\author{
Anna Kubicka \\ Wroclaw University of Science and Technology, ul. Bolesława Prusa 53/55 50-317 Wroclaw, Poland
}

ABSTRACT

The aim of a metrological analysis of the Machu Picchu site is to verify the hypothesis on the functioning of the imperial system of length measurement which was used by the Incas during measurement and construction processes. Data for metrological analyses were obtained from 3D laser scanning as 3D point cloud from where desired length measurements were collected. As far as the research method is concerned, a statistical model of a cosine quantogram was used to find a unit of design from a data set. The method has successfully been introduced during the analysis of architectural sites of the Mediterranean culture but never has been applied in regard to pre-Columbian archaeology. Statistical approach in this study will reveal new information about Inca urban planning based on the elements of architecture design.

\section{Section: RESEARCH PAPER}

Keywords: point cloud; length measurements, Inca architecture; statistic

Citation: Anna Kubicka, The metrological research of Machu Picchu site. Application of a cosine quantogram method for 3D laser data, Acta IMEKO, vol. 6, no. 3, article 8, September 2017, identifier: IMEKO-ACTA-06 (2017)-03-08

Section Editor: Sabrina Grassini, Politecnico di Torino, Italy

Received March 14, 2017; In final form July 31, 2017; Published September 2017

Copyright: ( $) 2017$ IMEKO. This is an open-access article distributed under the terms of the Creative Commons Attribution 3.0 License, which permits unrestricted use, distribution, and reproduction in any medium, provided the original author and source are credited

Funding: This work was supported by National Science Centre of Poland

Corresponding author: Anna Kubicka, e-mail: kubicka.ania@gmail.com

\section{INTRODUCTION}

During the expansion of the Inca empire from about 1430 to the Spanish conquest in 1532, (chronology based on John Rowe [1]) the Inca created an infrastructure as well as small and large settlements like a read network, vast irrigation system, agricultural terraces, suspension bridges and many more to launch a massive construction program which marked their presence across the Andean region. One of these settlements was Machu Picchu - an architectural investment generally associated with the Inca Pachacuti.

Beginning with the Bingham publication [2] Machu Picchu has been identified as a fortified city, outpost into tropical forest, a sanctuary dedicated to the moon, a center for "Chosen woman", the last refuge of Incas, a ceremonial canter. In spite of theoretical discussions about the function, the masonry of buildings in Machu Picchu is without doubts very fine and varied, without adobe bricks. These features and the presence of temples and sacred places on Machu Picchu indicate that it was a ceremonial center of great importance. The state wanted to show imperial investment and firm an intention of their presence in the area to the neighboring people. Nonetheless, the settlement does not have distinctive characteristics for a city with a probable population of one thousand inhabitants [3].

The settlement is divided into agricultural and urban zones with an entrance to the residential area from the south (Figure 1). The general layout of the settlement seems not to be achieved coincidentally but rather deliberately planned. It is visible in the spatial organization of the complex where each sector has a specific border carefully arranged on andenes (agricultural terraces). A water system must have been planned earlier in order to create a water channel system to all sacred structures on Machu Picchu.

The purpose of this research is to look for a basic unit or units of measure (quantum), multiplication of which would help delineate the outline of the Machu Picchu site. Search for a unit of design could determine the fact if the Inca used one imperial 


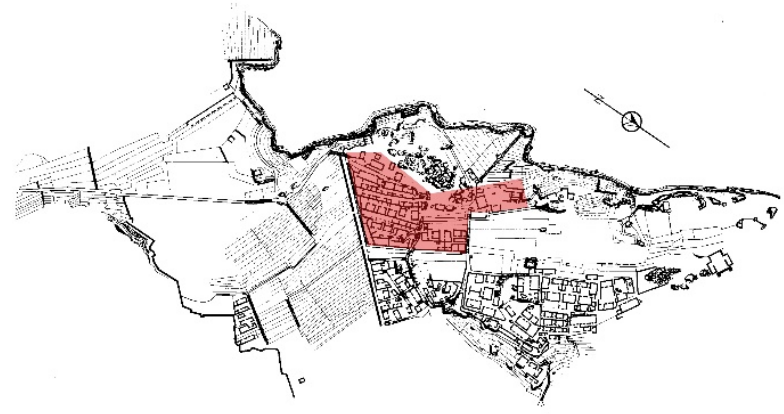

Figure 1. Plan of Machu Picchu with a marked area of investigation, source: G. Gasparini, L. Margolies, Inca architecture, Indiana University Press, 1980, p. 89.

measurement systems and construction rules in their urban planning or, quite the contrary. The ethnic diversity of people working on the construction of the Machu Picchu settlement brought with them a local tradition of measurement which caused more than one quanta in building architecture.

A statistical model of a cosine quantogram has successfully been implemented during the analysis of architectural sites of Mediterranean culture as well as European medieval urbanism [4]. Written sources from Greek, Roman (e.g. Isidore of Charax, Sextus Julius Frontinus, Lucius Junius Moderatus Columella) or Egyptian times give an opportunity to prove the usage of the metrological system in urbanism or architectural design.

\section{INCA MATHEMATIC PRECISION}

As John Rowe said some years ago, "Information on Inca units of measurement is relatively abundant, but so scattered and unsystematised as to give the impression that the Inca had no very precise standards. Actually, Inca skill in engineering works almost required a system of measurement at least as exact as that in use in 16th-century Europe" [5].

The art of cutting stones is, without a doubt, a very astonishing achievement of precision. It gives an impression that all Inca buildings were constructed of cut and fitted stonemasonry, but most of them were built of semi-cut or unworked fieldstones laid up in an argillaceous mortar. Undoubtedly, finely worked stones show an important function of a building but it does not determine an interpretation. In the Machu Picchu case, most buildings were constructed with mortared fieldstone masonry. In this construction, masonry is quite varied. In the walls, corners or frames of doors or niches stones were partially worked to fit into their position as well in corners of buildings where headers and stretchers are alternated providing excellent stability. Fieldstone masonry may have been coursed or uncoursed which depends on the shape and size of stones used. In coursed masonry stones are roughly the same height. They are usually 65 to $90 \mathrm{~cm}$ thick, but most of them measure close to $80 \mathrm{~cm}$ [6]. The precision in Inca masonry and civil engineering was not only present in this field of Inca material culture. Knotted string devices: quipu and an abacus - calculating devices - express Inca mathematical knowledge. Construction and use of quipu were mentioned in many Spanish sources as an extremely accurate accounting device. Data was encoded there using a decimal system indicated by the size and position of the knots. Marcia and Robert Ascher [7] provided some ideas concerning Inca mathematical abilities based on their studies of quipus: arithmetic ideas used by incas must have included at a minimum: addition, division into equal parts, division into simple unequal fractional parts, and multiplication of integers by integers and fractions.

\section{ARCHITECTURE AND METHODS OF BUILDING LAYOUT}

The area of the empire was covered by many different ecological zones so to conquer this varied landscape the Inca introduced architectural practice which could have adapted to these diverse regions and climates. Alexander von Humboldt, the German naturalist from early nineteenth century described Inka architecture as: "uniformity of construction... One should think that a single architect has built this large number of monuments" [8]. In inca architecture, a basic form of settlement exists which is a single-room structure. Based on the older central Andean building tradition this form was used to create a diversity of settlement types across the Inka Empire. They created a variation of form by making small but important changes, which allowed to enrich functionality and made architecture highly standardized. Structural elements of Inca architecture are constantly repeated. The interior of buildings is occupied with niches or windows arranged in a row in specific intervals, trapezoidal shaped with the shortest side on top. They placed them in all kinds of buildings (not only in temples like other Andean cultures.) Niches are usually situated on 120 to 150 centimetres above the floor level and their functions are different, depending on their location and size. The doorways are of similar shape, and on both these elements, Incas located a monolithic stone or wooden lintel. Last architectural detail visible inside and outside of a building structure are pegs. Outside they were used to tie a roof to a gable wall and inside probably as hangers located symmetrically between the niches on the same height.

A distinctive feature of Inca walls, which obviously has an influence on architectural planning, is the construction of battered walls. These have a sloping or trapezoidal cross section (from 3 to 5-degree), which is also often visible in a plan of a building. The function and purpose of this feature is based on statics of a building, where the thrust of the roof beams with a thick thatch roof could be more easily absorbed. Based on Wedge-stones, found in situ on Ollantaytambo, we can assume that some of the walls were constructed simultaneously from both ends and the working groups reached a point where was a gap to put only one more stone from the front. This type of wedge stones were set in a regular way on sites like Qorikancha, Saqsaywaman [9]. That is not a pattern of wall construction. Yet careful observation of construction features is needed for each type of wall.

Based on the knowledge of Inca architecture features building layout existed at least of three levels: a foundation, a level of niches or windows and occasionally a floor level where there is a doorstep in situ. These studies are focused on noninvasive techniques of documentation so it is not possible to reach a foundation level or even establish an assumption level because of the irregular bedrock of the mountain. In buildings where the floor level is preserved by a doorstep, a layout of the building is reconstructed but in most cases, it is not visible. However, a known level of construction remains on the elevation of niches and windows. They are wrapped around all four walls with a symmetrical distance between them. Measurements of niches and windows can be different from 
building to building but their arrangement on the wall is standardized. They are always symmetrically oriented on the wall with a door in the middle or two doors on equal distance, so it means that a length of the wall has to be known previously. Niles [10] presented a theory that the walls were built up to the desired height of the sills of the niches. Then the frames of niches were constructed at the desired intervals. When all the frames had already been placed, gaps between them were filled and additional courses of masonry laid on the top (Figure 2).

For that reason types of length measurements included in the dataset were on the level of niches which most likely have standardized measurements due to their uniformity in buildings and in some cases layout of the floor level.

\section{METHODOLOGY}

\subsection{Quantum model}

Due to the survival of measuring devices like rods or written sources which confirmed a design unit of measure it is possible to determine the fundamental quantum underlying the design and construction. However, for the cultures without this kind of established knowledge, a certain solution is to derive a basic unit of length from architectural dimensions. The length of architecture elements like blocks of stones or decorative elements could be described as muliplication of a basic unit plus small error caused by ancient building execution, where a type of hand tool did not provide a great precision for workers. Because of the same manual reason an error could be created by modern measurement techniques. Using statistical methods it is possible to derive a basic unit of design from a set of lenght measurements.

The cosine quantogram method used in this study was developed by D. G. Kendall [11] for detecting a quantum (the basic unit of design) of an unknown size from a set of data. In the case of Inca architecture each building dimensions of Machu Picchu $y$ can be described as an integer $M$ multiples of the basic unit: $q$, plus an error $\varepsilon$ as an uncertainty or margin of error of a measurement.

$y=q M+\varepsilon$.

In (2) $\varepsilon$ which is significantly smaller than $q$ is analyzed and then the formula calculates an amount which clusters around $q$. Results of the right candidate for a quantum $(q)$ are presented on a line graph as the highest peak (Figure 3 ). $N$ in the formula is a number of dimensions:

$$
f(q)=\sqrt{2 / N} \sum_{i=1}^{n} \cos \left(\frac{2 \pi \varepsilon_{1}}{q}\right) \text {. }
$$

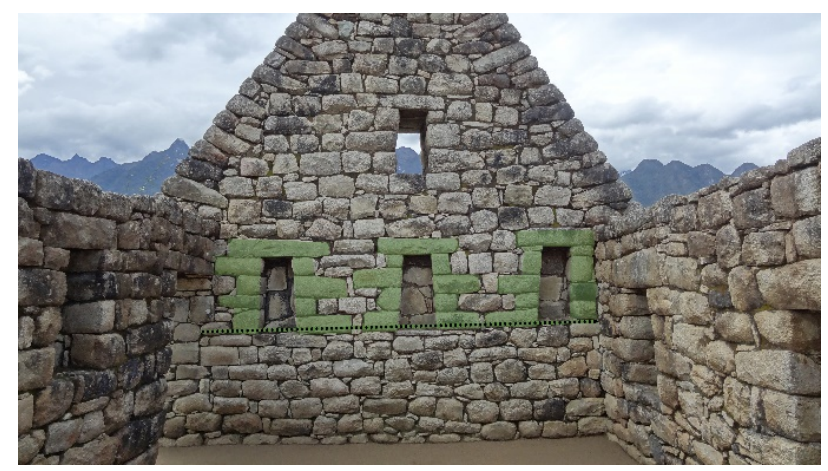

Figure 2. View inside the Inca building on Machu Picchu. Construction level of niches marks with a line of dots; photo: author.

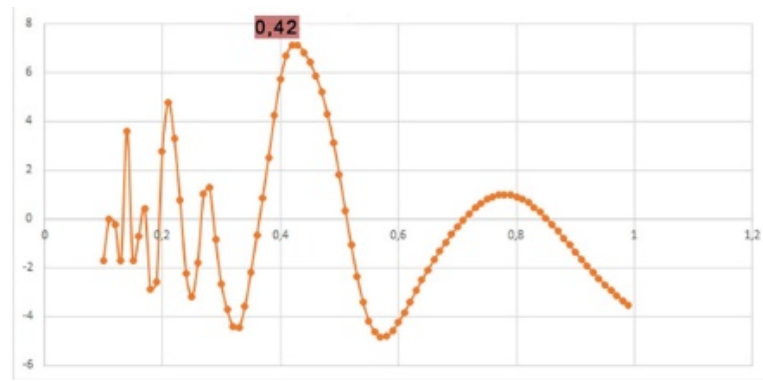

Figure 3. Graph presenting a quantum for sector 2B with a score 6.7 (significance level of a peak).

For a purpose of the research on Machu Picchu site, cosine quantogram formula was implemented into a JavaScript to simplify the calculation. All collected data in .txt format is imported with information about searching scope and value of division.

Works of other scholars proof that the cosine quantogram method encountered a problem if more than one quantum exists in a set of data [12]. For this reason, the Machu Picchu site was divided into architectural groups with the same function or construction and further calculated separately.

\subsection{The sample- Length measurements from $3 d$ point cloud.}

All the data has been collected from the 3D point cloud generated by $3 \mathrm{D}$ laser scanners and Multistation in recent years and reached a final stage this year. However, for a purpose of this paper around $50 \%$ of the scanned site was investigated and another half is currently in processing (Figure 1). In spite of this a set of data should be considered as one integral part because the area of the 3D point cloud constitutes an upper part of an architectural complex of Machu Picchu, where the lower part is on the opposite site of the Main square (Plaza principal). This division in Inca urbanism was presented in many settlements (banan-upper part and burin-lower part) [13] so these studies give an opportunity to check if a division in a metrological system of this two sectors exists for this particular settlement.

The 3D point cloud obtained from 3D laser scanning or LiDAR as a type of documentation gives, at that moment in archaeological studies, the most precise measurement results especially if an object is not regular and simple in its form. Furthermore, this allowed to create, directly from the obtained data, section and geometry reconstruction for some nonaccessible areas. Based on these features for the purpose of $3 \mathrm{D}$ documentation and these studies mostly the 3D scanner Leica ScanStation P40 (accuracy $3 \mathrm{~mm}$ at $50 \mathrm{~m} ; 6 \mathrm{~mm}$ at $100 \mathrm{~m}$ ) was used by a team from 3D Scanning and Modelling Laboratory (Wroclaw University of Technology) and The National Archaeological Park of Machu Picchu.

The dataset collected from the 3D point cloud was first transformed into vectorised plans and sections. Each plan contains desired measurements that were created as a line from the pick points (Figure 4). Data from the upper part of the urbanized site of Machu Picchu was divided into separate architectural groups, based on subdivision of modern site organization (Figure 5).

\section{CONCLUSIONS}

The residential area was divided into three groups: $2 \mathrm{~A}, 2 \mathrm{~B}, 3$ with the following numbers of measurements: $50,84,34$. A 


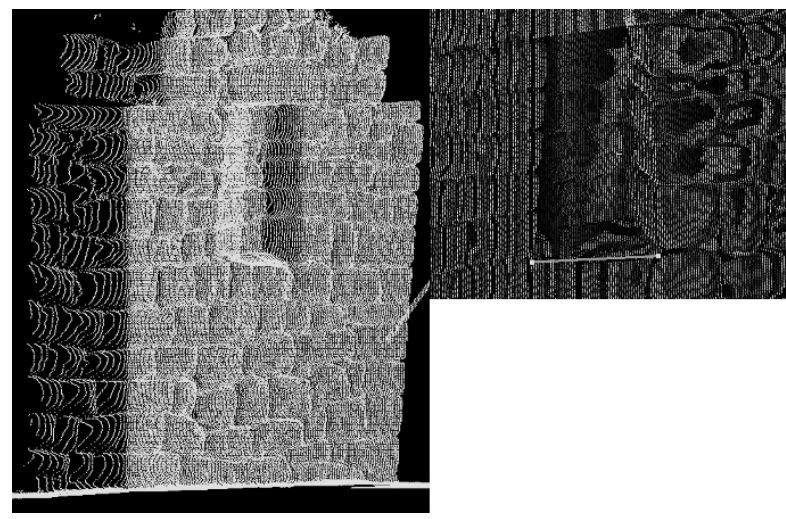

Figure 4. Example of the 3D point cloud during a preparation of data in Leica Cyclon.

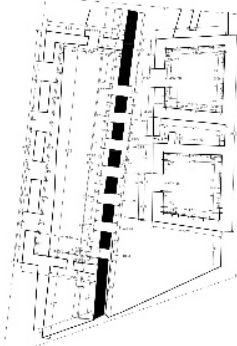

SECTOR $2 \mathrm{~B}$

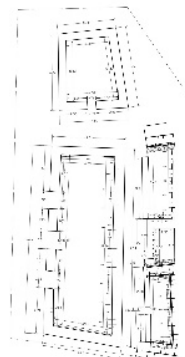

SECTOR 2A

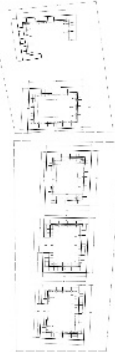

SECTOR 3

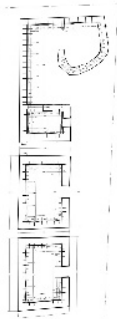

SECTOR 4
TTMPI.TOF THT SIN
Figure 5. Architectural groups of building measurements.

sector with a temple of the sun was created separately and included 128 measurements. The building of the so called Royal estate has 60 numbers of length measurements.

The distribution of all measurements suggests that two quanta may exist in the investigated data set: $0.27 \mathrm{~m}$ and 0.41 to $-0.44 \mathrm{~m}$. The estimation of the quantum $q$ for the residential sectors $2 \mathrm{~A}, 2 \mathrm{~B}$ and 3 is $0.41-0.43 \mathrm{~m}$ (Figure 6). The estimate of $q$ for the temple of the sun and for the building of sacred square is $0.27 \mathrm{~m}$ (Figure 7). Accompanying buildings of the temple has quantum $0.42 \mathrm{~m}$. For a royal estate area estimate $q$ is $0.44 \mathrm{~m}$.

There is no significant difference of quantum between the residential buildings and storage buildings: 0.41 to $0.44 \mathrm{~m}$. However, for sacred buildings, the quantum is completely different: $0.27 \mathrm{~m}$.

In order to exclude senseless quanta, lower and upper bounds were placed into a program to the limited value of quantum: 0.02 to 1.60 meters. Measurement systems based on body proportions are still common in Latin America. The smallest unit of measure is the finger: between 0.05 and $0.06 \mathrm{~m}$ and upper bounds capture the estimated value of fathom: 1.62 $\mathrm{m}$ [14].

The result of a quantum could be compared with the body proportion of cubit (quechua: khococ) [15] as a distance around $0.45 \mathrm{~m}$. For $0.27 \mathrm{~m}$ an equivalent in the human proportion in Latin America does not exist, because a length of the foot is usually $0.25 \mathrm{~m}$. It is possible that information about this unit of measurement does not exist in Hispanic sources but it fits as a part of fathom measure: $6 \times 0.27=1.62 \mathrm{~m}$.

Throughout the history of civilization, the system of urban planning defined the level of development. Inca

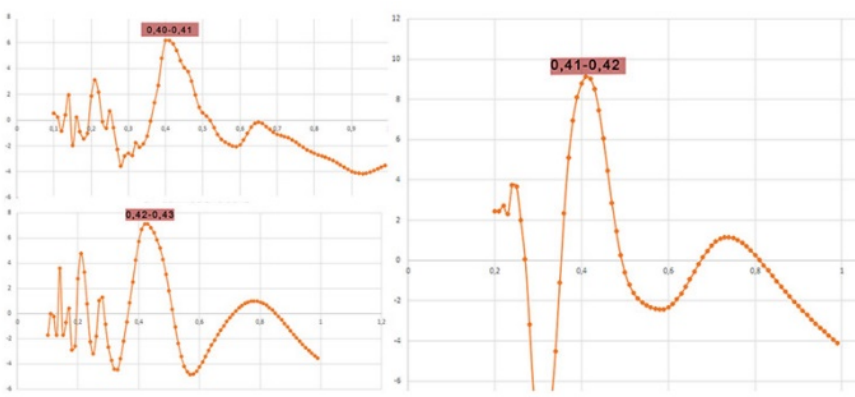

Figure 6. Results of quantum for residential sector.

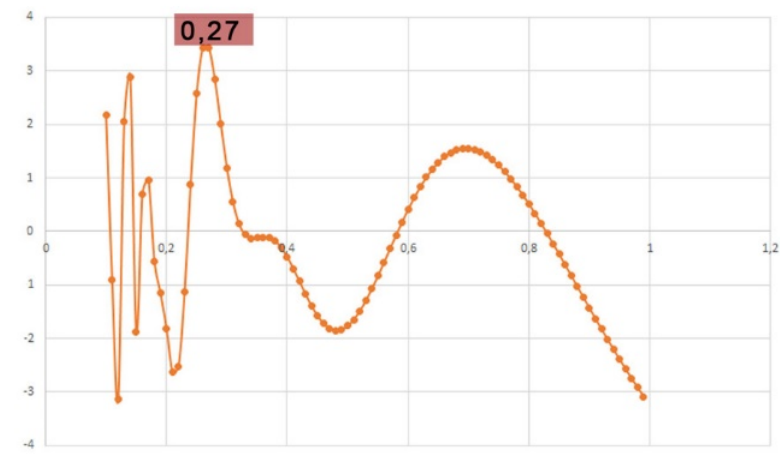

Figure 7. Results of quantum for the sacred square and the building of the sun temple.

architects/engineers and stone masons were professionals excluded from labour tax. They were supported by the state and worked on the building project but a scale of the participation in the construction process of the settlements plans is unknown [16]. Two significant length measurements were used in the residential sector of Machu Picchu, which suggests the stronger influence of imperial regulations. This phenomenon shall complement our knowledge of Machu Picchu, as well as other sites on the Inca territory, in terms of function and the process of creation.

\section{REFERENCES}

[1] J. Rowe, "Inca culture at the time of the Spanish conquest", in: Julian H. Steward (Ed.) Handbook of South American Indians, vol. 2.,June 2012, pp.323-325.

[2] H. Bingham, H. Thomson, Lost City of the Incas, Phoenix Press 2003.

[3] G. Gasparini, L. Margolies, Inca architecture, Indiana University Press, 1980, pp. 79-91.

[4] J. Pakkanen, "Deriving ancient foot unit from building dimensions: a statistical approach employing cosine quantogram analysis", in: Burenhult, G. and J. Arvidsson (eds.) Archaeological Informatics: Pushing The Envelope. CAA2001; Cox S. M., Determining Greek Architectural Design Units in the Sanctuary of the Great Gods, Samothrace: Application of and Extensions to the Cosine Quantogram Method, web source: https://etd.library.emory.edu/view/record/pid/emory:19n1r (09.12.2014); Crummy P., "The system of measurement used in town planning from the north to the 13-th cent.", in: AngloSaxon Studies in Archaeology and History, (Ed.) Hawkes, D .Brawn., Campbel, Oxford 1979.

[5] S. Niles, Callachaca: Style and status in a Inca community. Iowa city 1987 , pp. $217-225$.

[6] J. Rowe, "Inca culture at the time of the Spanish conquest", 
in: Julian H. Steward (Ed.) Handbook of South American Indians, vol. 2.,June 2012, p. 323.

[7] J.P. Protzen, Inca Architecture and Construction of Ollantaytambo, Oxford 1993, pp. 157-164.

[8] M. Ascher, R.Ascher, Mathematics of the Incas: Code of the Quipu, New York 1981, pp. 133-143.

[9] A. Humboldt, Sites des cordillères et monuments des peoples indigènes de l'Amérique, Paris 1896,p. 449.

[10] J.P. Protzen, Inca Architecture and Construction of Ollantaytambo, Oxford 1993 pp. 195-223.

[11] D.G. Kendall, Haunting quanta, Philosophical Transactions of the Royal Society of London, A276, 1974, pp. 231-66.

[12] S. Mustonen, Hunting multiple quanta by selective least squares, websource:

http://www.survo.fi/papers/HuntingQuanta2012.pdf (10.10.2015).

[13] G. Gasparini, L. Margolies, Inca architecture, Indiana University Press, 1980, pp. 79-82.

[14] Agurto Calvo, S., Estudios Acerca de la Construccion, Arquitectura y planeamiento Incas, Camera Peruana de la Construccion, Lima 1987, pp. 255-274.

[15] M. Rostworowski de Diez Canseco, Mediciones y computos en el Antiguo Perú, Cuadernos Prehispanicos 6, Seminario Amerycanista 1988.

[16] J. Hyslop, Inka settlement planning, Austin 1990, pp. 27-28. 